\title{
Leonardo as Artist, Scientist, Engineer
}

\author{
Diana Dabby \\ Franklin W. Olin College of Engineering
}

\begin{abstract}
Students find Leonardo's complex persona and the richness of his artistic and scientific inquiry vital for understanding Leonardo, ingegnere (the engineer). Taking his life and work as its domain, Leonardo as Artist, Scientist, Engineer develops the following skills in its range: discovery, discussion, identifying a monograph's major points, building a scaffold of knowledge, individual research, and creative conveyance of information. It further addresses the timehonored trio of reading, writing, and arithmetic (or Italian high finance: how many silverpoint pencils can you buy for 120 soldi? and why should you care!).
\end{abstract}

\section{Introduction}

Starting with four seminal figures - Giorgio Vasari, ${ }^{1}$ Goethe, Freud, and Kenneth Clark ${ }^{2}$ — and a factual chronology of Leonardo's life, the seminar examined LdV from five perspectives ranging from generally agreed-upon facts to a provocative "inside his head" approach. Subsequent comparisons with passages in da Vinci's Notebooks, the Florentine State Archives, contemporaneous letters, and eyewitness accounts helped shed light not only on the five slants provided above, but also on his creative process.

A figure such as Leonardo can inspire students to view engineering as an expansive, imaginative art. As such, he joins a pantheon of "heroes" whose inventiveness proves motivating both inside and outside the classroom. In contemplating da Vinci's creative process, it can be helpful to bring in others, such as Alexander Graham Bell and Thomas Edison, ${ }^{3}$ whose mental processes have been admirably discussed and contrasted. ${ }^{4}$ In a future iteration of the seminar, such context will be feasible since the time allowed for the class will nearly triple. During the Fall 2001 term, the seminar ran for five weeks.

Roughly four and a half two-hour classes (nine class hours out of 20 total) dealt with Leonardo's life and ways of working within the context of his time. His Notebooks, paintings, anatomical studies, military engineering, and inventions comprised the remaining classes. I turned the paintings over to the students. Each claimed one or two. Encouraged to convey their research to the class in any way that got the material across, they showed great energy and creative flair with their Slide Show. They then voted on what topics to cover next, choosing to focus the remaining classes on Leonardo's anatomical studies, LdV as military engineer, and his inventions. Based on their enthusiasm for individual research, as displayed in the Slide Show, I then turned the inventions over to them. Each claimed one and we declared our last class "Invention Day", featuring the student's presentations on Leonardo's machines. 


\section{Engineering discovery}

In 1482, at the age of 30, Leonardo penned a draft of a letter in one of his Notebooks. Addressed to the dominant figure in Milanese government, Ludovico Sforza, the letter extols Leonardo's abilities as a military engineer and then parenthetically closes with an aside that can be paraphrased, "By the way, in times of peace, I can also design buildings, draw, paint, and sculpt."

\section{Draft of a Letter from Leonardo to Ludovico Sforza, in which LdV offers his services and states his abilities (c. 1482)}

Most illustrious Lord, Having now sufficiently considered the specimens of all those who proclaim themselves skilled contrivers of instruments of war, and that the invention and operation of the said instruments are nothing different from those in common use: I shall endeavor, without prejudice to any one else, to explain myself to your Excellency, showing your Lordship my secrets, and then offering them to your best pleasure and approbation to work with effect at opportune moments on all those things which, in part, shall be briefly noted below.

(1) I have a sort of extremely light and strong bridges, adapted to be most easily carried, and with them you may pursue, and at any time flee from the enemy; and others, secure and indestructible by fire and battle, easy and convenient to lift and place. Also methods of burning and destroying those of the enemy.

(2) I know how, when a place is besieged, to take the water out of the trenches, and make endless variety of bridges and covered ways and ladders, and other machines pertaining to such expeditions.

(3) Item. If, by reason of the height of the banks, or the strength of the place, and its position, it is impossible, when besieging a place, to avail oneself of the plan of bombardment, I have methods for destroying every rock or other fortress, even if it were on a rock, \&c.

(4) Again, I have kinds of mortars, most convenient and easy to carry; and with these I can fling small stones almost resembling a storm; and with the smoke of these cause great terror to the enemy, to his great detriment and confusion.

(5) Item. I have means by secret and tortuous mines and ways, made without noise, to reach a designated [spot], even if it were needed to pass under a trench or a river.

(6) Item. I will make covered chariots, safe and unassailable, which, entering among the enemy with their artillery, there is no body of man so great 
but they would break them. And behind these, infantry could follow quite unhurt and without any hindrance.

(7) Item. In case of need I will make big guns, mortars, and light ordnance of fine and useful forms, out of the common type.

(8) Where the operation of bombardment might fail, I would contrive catapults, mangonels, ${ }^{5}$ trabocchi, ${ }^{6}$ and other machines of marvelous efficacy and not in common use. And in short, according to the variety of cases, I can contrive various and endless means of offence and defence.

(9) And if the fight should be at sea I have many kinds of machines most efficient for offence and defence; and vessels which will resist the attack of the largest guns and powder and fumes.

(10) In time of peace I believe I can give perfect satisfaction and to the equal of any other in architecture and the composition of buildings public and private; and in guiding water from one place to another.

Item. I can carry out sculpture in marble, bronze, or clay, and also I can do in painting whatever may be done, as well as any other, be he who he may.

Again, the bronze horse may be taken in hand, which is to be to the immortal glory and eternal honor of the prince your father of happy memory, and of the illustrious house of Sforza.

And if any of the above-named things seem to any one to be impossible or not feasible, I am most ready to make the experiment in your park, or in whatever place may please your Excellency - to whom I commend myself with the utmost humility, \&c. ${ }^{7}$

Scholars have argued over the claims made in this letter, questioning whether Leonardo really had the technical expertise to substantiate them. Yet in perusing his drawings and the dates attributed to them, students find designs that support da Vinci's claims, among them a multibarreled gun (1482) providing "light ordnance of fine and useful forms, out of the common type", a siege machine (1480) functioning "where the operation of bombardment might fail", and a device for toppling siege ladders (1482). Later in 1485, his designs for "covered chariots, safe and unassailable", scythed cars, and giant crossbows appear in the Notebooks, as does his steam cannon (1487-89). ${ }^{8}$

Precedent becomes an issue here. Earlier military engineers had also advertised such devices, e.g., Konrad Kyeser designed a multi-barreled gun in 1405. Leonardo's drawings contribute improvements on many of these older designs, as in the armored tank where his real innovation lies in its mobility: hand-cranked by men with the cranks attached to horizontal trundle (roller) wheels which in turn are geared to the four driving wheels. ${ }^{9}$ 


\section{Classroom discussions}

Seminar topics ranged from LdV's modus operendi as an artist/researcher to his sodomy charge of 1476. The Renaissance biographer Giorgio Vasari comments on the first in recounting the story of Leonardo and the buckler (a shield) that his father asked him to make for a peasant on his farm.

... Leonardo started to think what he could paint on it so as to terrify anyone who saw it and produce the same effect as the head of Medusa. To do what he wanted Leonardo carried into a room of his own, which no one ever ent ered except himself, a number of green and other kinds of lizards, crickets, serpents, butterflies, locusts, bats, and various strange creatures of this nature; from all these he took and assembled different parts to create a fearsome and horrible monster which emitted a poisonous breath and turned the air to fire. He depicted the creature emerging from the dark cleft of a rock, belching forth venom from its open throat, fire from its eyes and smoke from its nostrils in so macabre a fashion that the effect was altogether monstrous and horrible. Leonardo took so long over the work that the stench of the dead animals in his room became unbearable, although he himself failed to notice because of his great love of painting. ${ }^{10}$

Vasari's Life of Leonardo contains errors and omissions that students recognize when they compare his account to a generally accepted chronology of LdV's life. Yet they also find great value in Vasari, especially when they become cognizant of Leonardo's own writings and those of his contemporaries. For example, Vasari's depiction of Leonardo's focus as shown in the buckler story gains credibility when students examine Leonardo's own writing:

... I have dissected more than ten human bodies, destroying all the other members, and removing the very minutest particles of the flesh by which these veins are surrounded, without causing them to bleed, excepting the insensible bleeding of the capillary veins; and as one single body would not last so long, since it was necessary to proceed with several bodies by degrees, until I came to an end and had a complete knowledge; this I repeated twice, to learn the differences.

And if you should have a love for such things you might be prevented by loathing, and if that did not prevent you, you might be deterred by the fear of living in the night hours in the company of those corpses, quartered and flayed and horrible to see. $^{11}$

Clearly, these two passages by Vasari and Leonardo describe the same focused, determined, perfectionist individual who observes every little detail, and performs accordingly.

IV. Identifying the major points of a thesis

Since its publication, Sigmund Freud's monograph Leonardo da Vinci and a Memory of his Childhood continues to incite both protest and praise. Like many scholars before them, some 
students found Freud's account offensive, while others felt Freud illuminated the murkier aspects of Leonardo's personal life and work. What truly united the class, though, was an exercise where they identified the major points of Freud's thesis. Once they got them on the board, those that "hated" Freud did not find his main points so far afield from their own growing sense of Leonardo, though Freud's logic leading to his conclusions still stirred dissent. Some of the points students culled from Freud's monograph found an echo in the voice of the honored art historian Kenneth Clark. Freud frankly discusses Leonardo's homosexuality, insisting that too many scholars ignore the whole picture of da Vinci. Clark also comments, "We cannot look at Leonardo's work and seriously maintain that he had the normal man's feelings for women. And those who wish, in the interest of morality, to reduce Leonardo, that inexhaustible source of creative power, to a neutral or sexless agency, have a strange idea of doing service to his reputation.", 12

Another insight promulgated by Freud concerns Leonardo's 'Virgin and Child and St. Anne.' The 1508 painting depicts three generations: St. Anne the mother of Mary, who is in turn the mother of the Christ Child. Freud claims that Leonardo painted St. Anne and Mary coeval because Leonardo had two mothers, his peasant mother Caterina who bore him out of wedlock and his step-mother Albiera whom his father married shortly after his birth. Clark supports Freud's interpretation of the nearness in age of the two female figures in the painting:

... I cannot resist quoting the beautiful, and I believe profound, interpretation that Freud has put on this picture. He imagines that Leonardo must have spent the first years of his life with his mother, the peasant Caterina; but a year after his birth his father married, and when Ser Piero found that his wife was unlikely to have children, he brought his love child to be looked after by her. In a sense, therefore, Leonardo had two mothers. And it is the unconscious memory of these two beloved beings, intertwined as if in a dream, which led him to dwell with such tenderness on the subject of the Virgin and St Anne. Whether or not this is true in fact, it seems to express the mood of the Louvre picture, and explains the apparent nearness in age of mother and daughter, the strange intermingling of their forms and their remote, mysterious smiles. ${ }^{12}$

Only 15 Italian St. Anne/Virgin/Child paintings exist prior to 1500 and only one of them has Anne and Mary coeval. Thus, Leonardo's depiction of mother and daughter as contemporaneous, coupled with its rarity, further buttress Freud's insight and Clark's concurrence. $^{13}$

\section{Building a scaffolding}

A continuing thread throughout the class-a scaffold of knowledge-acquires ever more dimension as students pursue their various researches. An evolving scaffold becomes the springboard from which students argue different points of view on LdV's life and works.

The factual chronology of Leonardo's life forms the essential skeleton of the scaffold. Asking students to prepare a list of differences between the chronology and Vasari's Life of Leonardo helps familiarize them with the bare facts of LdV's life, without requiring a memorization 
assignment. Keeping the facts straight proves helpful in arguing different interpretations of Leonardo's life and work, as provided by Vasari, Goethe, Freud, Clark, and denumerable contemporary scholars. It also raises the level of sophistication for ensuing class discussions. One such discussion centered on Freud's argument that much of Leonardo's character and work followed from the fact of his illegitimacy and the 3-5 years he spent alone with his mother Caterina. Freud presumes Leonardo as her sole companion during this time.

Examination of tax records shows that Leonardo, by the age of five, resided in the household of Ser Antonio, his paternal grandfather. Ser Antonio's 1457 tax record lists LdV as one of his dependents, or "mouths" (bocche), in the family household in Vinci. The document reveals Leonardo as the illegitimate son of Ser Piero and Caterina, that he is five years old, and that Caterina is now married to Accattabriga di Piero del Vacca da Vinci. This record confirms the chronology and also supports Freud's statement that Leonardo spent up to five years with Caterina.

Yet Freud's claim that Leonardo spent his first 3-5 years as his mother's sole companion loses credibility in light of another tax record - the 1460 tax return of Accattabriga, Caterina's husband. Completed in 1459, the return lists his bocche and their ages: Caterina 30, Piera (born 1454) 5, Maria 2. ${ }^{13}$ Clearly, Caterina had become intimate with someone, most probably Accattabriga, by 1453, one year after Leonardo's birth. Furthermore, by his second year, Leonardo had a sibling, Piera. With Piera (and probably Accattabriga) in the picture, the presumed solitude of Leonardo and his mother no longer holds much beyond a year.

\section{Individual research}

Students demonstrated a real love and talent for gathering, assimilating, and evaluating information. They enjoyed the freedom of researching a topic they had personally chosen and then presenting it to the class by any means that would effectively convey content in a memorable way. Students took ownership of two major topics in the class-Leonardo's paintings and his inventions. For the paintings, each student claimed one or several that revolved about a common theme. Thus, Nicholas Zola undertook the Madonna paintings ('Madonna and Child', 1476; 'Benois Madonna', 1478-80; 'Madonna Litta', c. 1480-1). Using Venn diagrams and a blackboard, he asked the class to observe the similarities in the paintings (where they intersected) and differences. Using this exercise, the class deduced which of the three Madonnas may not have been painted by Leonardo. Another student, Kathleen King, claimed the two 'Virgin of the Rocks' paintings (1482-3 and 1506-8) and gave the class one minute to look at the later version and then, while the earlier version was displayed, recount all the differences between the two. She then elaborated on the significance of the differences. Each person who could find a difference was rewarded with a chocolate bar - a very effective learning device!

For the inventions, students formed teams to produce "Invention Day." Each team chose from among the many categories of Leonardo's inventions: mechanics, hydraulics, aviation, and "other." In order to devise an informative, fun presentation for their peers, each team first surveyed da Vinci's work in a particular category and then presented selected inventions. For every chosen invention, students prepared a "patent" application, modeled loosely on the examples of U.S. patents brought into the class. Since patents require a search for precedence, 
students researched precursors for Leonardo's designs. For her individual invention, Leonardo's odometer, Joles Arnold built a model of his design-out of Legos. One of the group presentations involved a Quiz Show with an array of ordinary objects-bicycle, odometer, lighter, etc. The audience (our class) had to decide whether the everyday object had a precedent in LdV's Notebooks. Again, chocolate rewarded those who correctly deduced a precursor.

VII. Creative conveyance of material

As a result of the Painting Slide Show and Invention Day, students introduced the following pedagogical slants on the "presentation", all of which can be used in further evolutions of our seminar:

- The electronic skit with information conveyed via cyber actors.

- Sectional views of a painting to illustrate its materials, from the frame to the actual paint.

- A background "image history" that sets the context for LdV's radical departure, e.g., Leonardo's androgynous portrayal of St. John the Baptist cf. the rugged, masculine depictions that occurred earlier, as well as later.

- Use of Venn diagrams as a comparison technique.

- A timed quiz show (remember the prizes!) to stimulate and focus observation.

- Lyrics + tune: a song will get you every time, while conveying the essence of a work's conception.

- Identification of a motif and its variations through image and words.

- A witty handbook, low tech and tactile.

- Becoming Leonardo and staying in character, while talking about a particular period in his life.

VIII. Reading, writing, and Italian high finance

Reading focused on information-gathering, interpretation, and "detective work." Goethe's monograph "Observations on Leonardo da Vinci's celebrated picture of 'The Last Supper" offers students the opportunity to read one famous artist's views on the work of another. Students read Goethe with a specific mission in mind: to write a biographical chronology of the "life" of 'The Last Supper.' And it is quite a story. One could not imagine the pure folly and unfortunate circumstances that dogged the life of this painting. In doing so, students face a paradox. The painting's deterioration stems in large part from two problems: shoddy construction of the monastery wall on which it exists and Leonardo's decision to use a new technique to prepare the wall so that he could avoid painting a fresco, which requires quick execution. As a painter Leonardo worked slowly, preferring oil and tempura, which allowed his work to unfold according to his own inner clock. This experiment-concocted by one who embraced technology and advertised his technological acumen-failed utterly. Leonardo's technique for preparing the wall of the Santa Maria della Grazie refectory ruined his efforts even as he continued to work on the painting:

Accordingly it has been found, after a careful inquiry, that Leonardo coated the plaster of the wall with a mixture of mastick [a yellowish resin], pitch and other ingredients, laying it on with a hot iron. And, in order to obtain a perfectly 
smooth surface, as well as an additional security against any action from without, he put upon the whole a slight coating of white lead, mixed with some fine, yellow, argillaceous [clay] earths. But this very precaution seems to have proved injurious to the work; for, although this last coating, at first, while the colors of the picture, laid in it, contained sufficient nourishment to feed it, was, for some time, preserved; yet, when the oil was, by degree, dried up, that effect ceased, and the surface cracked. The moisture of the wall then forced its way through, and generated the mold, by which the picture was ultimately effaced. ${ }^{14}$

Writing consisted of two short essays - one on Freud's major points and another on the significant observations made by Kenneth Clark in his Leonardo da Vinci. Students also prepared "detective reports", e.g., detailing the differences between Vasari's Leonardo and the factual chronology agreed upon by most LdV scholars. For "Invention Day" students prepared a "quasi-patent" write-up on an invention of their choosing, as described above.

Arithmetic, Italian high finance, silverpoint pencils, and soldi came into play as students sought to answer the question of whether a reference to a certain Caterina in Leonardo's Notebooks does indeed refer to his mother:

Expenses of the Interment of Caterina [1494]

For the 3 lbs of tapers

For the bier

A pall over the bier

For bearing and placing the cross

For bearing the body

For 4 priests and 4 clerks

Bell, book and sponge

For the gravediggers

To the senior

For a license from the authorities
$27 \mathrm{~S}$

$8 \mathrm{~S}$

$12 \mathrm{~S}$

$4 \mathrm{~S}$

$8 \mathrm{~S}$

$20 \mathrm{~S}$

$2 \mathrm{~S}$

$16 \mathrm{~S}$

$8 \mathrm{~S}$

$1 \mathrm{~S}$

\section{$106 \mathrm{~S}$}

The doctor $2 \mathrm{~S}$

Sugar and candles

\section{$120 \mathrm{~S}$}

The above describes the expenses associated with a funeral. ${ }^{11}$ Leonardo is characteristically laconic regarding any personal associations in his Notebooks. People appear often as items in a ledger of expenses, especially those closest to him, such as his pupils. So the simple listing of expenses does not preclude a person of importance to him. The question really is: do these expenses represent a lavish funeral or are they the expenses one would associate with the burial of a more common person? (Leonardo did have a servant named Caterina, but she survived him and is named a recipient in his will). 
A possible clue to the value of 120 soldi appears in Leonardo's manuscripts. He writes twice in his Notebooks about the theft of a silver point pencil, the first valued at 22 soldi, and the second at 24 soldi:

Item: on the $7^{\text {th }}$ day of September [1490] he stole a silver point of the value of 22 soldi from Marco who was living with me, this being of silver; and he took it from his studio, and when the said Marco had searched for it a long while he found it hidden in the said Giacomo's box. ${ }^{11}$

Item: again, on the $2^{\text {nd }}$ of April [1491], Giovan Antonio having left a silver point on a drawing of his, Giacomo stole it, and this was of the value of 24 soldi. ${ }^{11}$

Assuming the cost of such a pencil remained fairly constant ( 24 soldi) between 1491 and 1494, Caterina's funeral expenses of 120 soldi amount to the cost of five silver point pencils - a drawing implement not so dear as to be irreplaceable, yet dear enough for Marco to search for it "a long while" and for Leonardo to notate the value in at least two instances of theft. Furthermore, comparing Leonardo's 1491 and 1494 itemizations, one silverpoint pencil at 24 soldi costs more than the services of four priests, four clerks, and one doctor!

\section{Remarks}

I designed eight homework assignments to support the above skills. The more challenging assignments occurred at the beginning of the class in order to help students enter LdV's world in a fairly sophisticated way (and also to productively use the 5-day and one-week intervals between classes that occurred at the start of the term). However, presenting them with an increased workload at the start of classes went against what they normally experience, i.e., a ramping up in workload at the end of term, not at the beginning. Once they realized it was only temporary, the "blitz" they experienced at the beginning began to pay off, giving them an appreciation for the issues surrounding Leonardo, issues that came to bear on their own research into his works. By the time the students presented the Slide Show, Invention Day, and journeyed into LdV's anatomical and military engineering, they had added considerable dimension to the scaffolding they built from earlier assignments.

\section{How the "Ten" helped launch LdV at FWO}

Encouraged to help shape the class, and take ownership of it, the ten students enrolled in the seminar effectively invented their class culture. Active participation in discussion reflected multiple points of view, insight, and catalyzed more discussion-centered classes. The participation factor, coupled with the difficulty of predicting how long certain class discussions might go, demonstrated a clear need for a semester-long seminar for greater flexibility. Their written assignments reflected points of view that often magnified the reading at hand, demonstrating the importance of every reader to the topic under review-a format that capitalizes on each student's "eyes" so that all benefit from one another's discoveries. Their active engagement in the seminar helps us to realize what is possible in terms of student involvement. Engendering a culture of open, collegial discourse, mixed with humor-something 
FWO's president has talked about as vital—-they are the first to have demonstrated this in a seminar setting at Olin. Their analysis of the material at hand often led discussion into areas, complementary and unanticipated, that generated much spontaneity. They remained open and receptive to challenge (especially helpful when trying out new approaches!). Their feedback was consistently constructive and effective. As a result, I was able to continually evolve the class along lines that seemed to engage all of us. When they discussed and voted our final topics of the term, they helped me to see where the class wanted to go. They took ownership of the Slide Show — on a consistently high level—demonstrating the power of student-driven learning. "Invention Day" grew out of this experience. In Olin's end-of-term assessment, students addressed the question of whether the class "exercised their creativity." Two of the nine respondents checked "agree", while the remaining seven marked "strongly agree."

XI. One last, lingering thought ...

To establish a backdrop for Leonardo, our seminar opened with a discussion of "What constitutes greatness?" The conversation remains on-going, both generally and specifically with regard to LdV. The five-week module both illuminated and hid his complexity. On the one hand, we managed to explore many competing aspects of his life and work. Yet, each road led to myriad others, for which, to borrow a phrase from his Notebooks, we were "hindered neither by avarice nor negligence, but simply by want of time." 11

Bibliographical Notes

${ }^{1}$ Giorgio Vasari (1511-1574), generally regarded as the first art historian, published his Lives of the Artists in 1550. A second revised edition appeared in 1568 .

${ }^{2}$ A graceful writer and instinctively undogmatic, Kenneth Clark (1902-1983) set a high bar for art criticism in the $20^{\text {th }}$ century. His writings have become models for their insight, knowledge, and scholarship.

${ }^{3}$ Hughes, T. Networks of Power: Electrification in Western Society, 1880-1930. Baltimore: John Hopkins University Press (1983).

${ }^{4}$ Gorman, M. and Carlson, W. Interpreting Invention as a Cognitive Process: The Case of Alexander Graham Bell, Thomas Edison, and the Telephone. Science, Technology, \& Human Values, 15 (2), 1990, 131-164.

${ }^{5}$ A military apparatus for throwing stones.

${ }^{6}$ A device for knocking down walls and other structures.

${ }^{7}$ Goldscheider, L. Leonardo da Vinci. London: Phaidon (1959).

${ }^{8}$ Letze, O. and Buchsteiner, T., eds. Leonardo da Vinci. Ostfildern-Ruit: Verlag Gerd Hatje (1997).

${ }^{9}$ Gibbs-Smith, C. The Inventions of Leonardo da Vinci. Oxford: Phaidon (1978). As Gibbs-Smith notes, LdV made an obvious error in his drawing (at least to modern eyes). Scholars have debated whether or not the error was deliberate.

${ }^{10}$ Vasari, G. Leonardo da Vinci. Lives of the Artists. Translated by G. Bull. London: Penguin (1987).

${ }^{11}$ Da Vinci, L. Notebooks. Vol. II. Compiled and edited by J. P. Richter (1883). New York: Dover (1970).

${ }^{12}$ Clark, K. Leonardo da Vinci. Penguin (1993).

${ }^{13}$ Collins, B. Leonardo, Psychoanalysis, and Art History. Evanston: Northwestern University Press (1997).

${ }^{14}$ Goethe, J. Observations on Leonardo da Vinci's celebrated picture of 'The Last Supper'. In Goethe on Art. Selected, edited and translated by J. Gage. Berkeley: U. Calif. Press (1980).

DIANA DABBY

Proceedings of the 2002 American Society for Engineering Education Annual Conference and Exposition Copyright (C) 2002, American Society for Engineering Education 
Diana Dabby, Asst. Professor of Electrical Engineering and Music at Franklin W. Olin College of Engineering, has taught at MIT (electrical engineering), Tufts (music composition), and Juilliard (graduate studies). She received her $\mathrm{PhD}$ from MIT (EECS) for her thesis Musical Variations from a Chaotic Mapping. As a pianist and composer, she has had performances in New York at Weill (Carnegie) Recital Hall, Merkin Concert Hall, and in Boston at Jordan Hall, Symphony Hall, as well as Tanglewood. 